\title{
Malignant Cerebral Neoplasm
}

National Cancer Institute

\section{Source}

National Cancer Institute. Malignant Cerebral Neoplasm. NCI Thesaurus. Code C4577.

A malignant neoplasm involving the cerebrum. 